\section{Instituição se engaja ainda mais em prol da ciência brasileira}

Quando surgiram, no final do século XVII, as academias de ciências tinham como objetivo reunir talentos, acelerar os avanços e intercâmbios na ciência. Com o tempo o papel dessas instituições se ampliou, passando a incluir incentivar jovens para a carreira científica, realizar diagnósticos e aconselhar os tomadores de decisão sobre as políticas científicas e tecnológicas. Há cem anos, celebrados no dia 3 de maio, era inaugurada a Sociedade Brasileira de Ciências sob a presidência do francês, naturalizado brasileiro, Henri Charles Morize (1861-1930). Em 1921, a sociedade mudaria seu nome para Academia Brasileira de Ciências (ABC).

Embora sua missão siga a tradição internacional, a entidade brasileira tem peculiaridades. Jacob Palis, presidente da ABC de 2007 a abril deste ano, lembra que o fato do país ser muito grande tornou importante a atuação da instituição nas várias regiôes por meio de seis vice-presidentes regionais e quatro diretores. Com isso, há maior entrosamento e representação de todas as regióes e, também, mais equilíbrio na eleição dos membros afiliados. Em cem

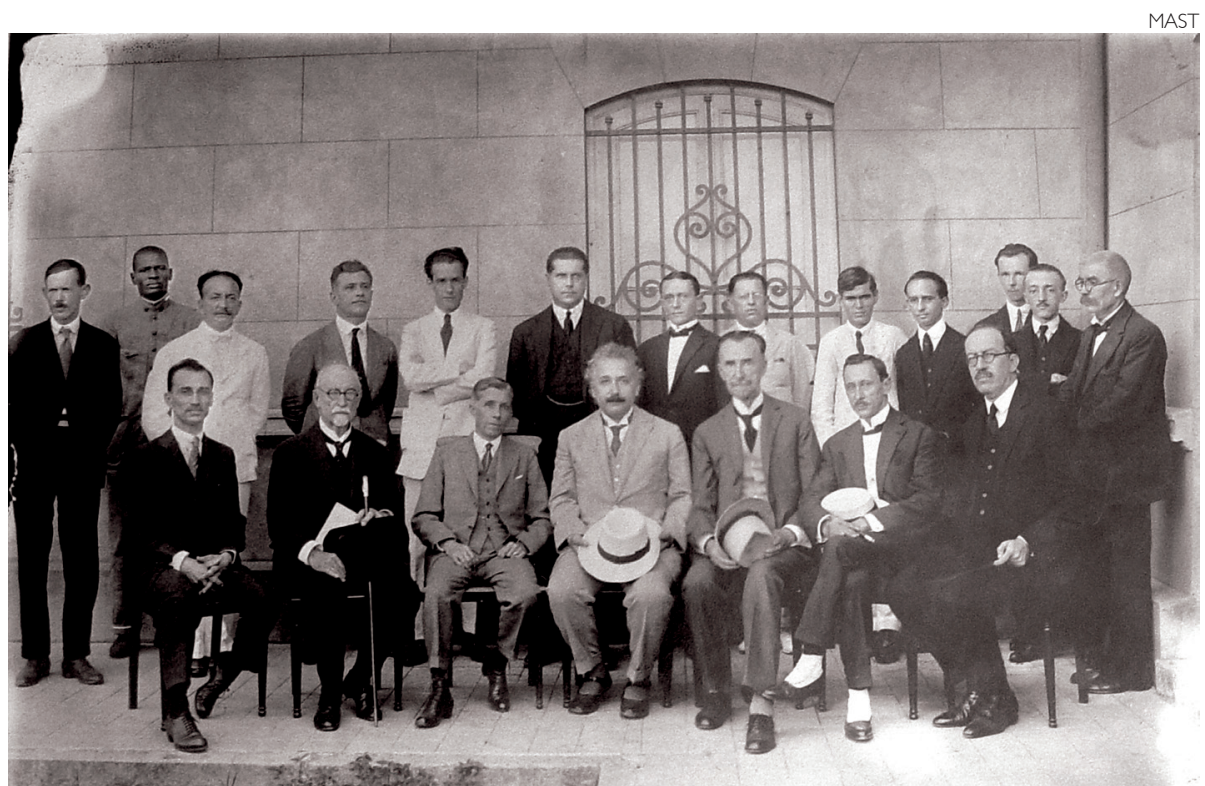

Em visita ao país em 1925, Albert Eistein se tornou membro correspondente da $A B C$

anos de atuação a $\mathrm{ABC}$ teve papel marcante em conquistas para a ciência brasileira, como os esforços na introdução da radiodifusão no país (1923), a criação do Conselho Nacional de Desenvolvimento Científico e Tecnológico (CNPq), em 1949, e da Financiadora de Estudos e Projetos (Finep), em 1969.

"Na década de 1930, frente à percepção de que no Brasil era impossível manter a associação [ABC] sem o apoio do Estado, iniciou-se um processo para provar a utilidade prática da ciência, e isso fortaleceu-se ao ponto de a $\mathrm{ABC}$ exercer, hoje, um forte papel na definição de políticas públicas nas várias áreas de sua atuação", analisa José Murilo de Carvalho, historiador e membro da ABC desde 2003. Em 1967, o go- verno federal reconheceria a $\mathrm{ABC}$ como parte integrante do sistema de ciência e tecnologia nacional e como entidade competente a fornecer pareceres sobre o estado de C\&T no país, por meio do II Plano Básico de Desenvolvimento Científico e Tecnológico. O documento legitimou a academia e permitiu que a mesma pleiteasse recursos governamentais para suas atividades.

A ABC tem produzido documentos relevantes para as políticas científicas e tecnológicas do país como "Uma política de Estado para ciência, tecnologia e inovação", enviado em 2003 a todos os candidatos à presidência e que acabou sendo incorporado no plano de CT\&I do Ministério da Ciência e Tecnologia (MCT), em 2007. Há também a 
publicação de materiais com temática específica, por exemplo sobre pesquisas na Antártica brasileira, a crise hídrica, educação, Amazônia, sustentabilidade, entre outros. "É uma pena que nossos governantes não utilizem esse valioso material, escrito por cientistas altamente especializados em suas áreas, até mesmo para tomada de decisão e implementação de políticas. Em outros países, os governos costumam ouvir mais seus cientistas. As academias de ciências são um canal de interlocução", lamenta a bióloga Débora Foguel, acadêmica desde 2008.

MULTIDISCIPLINAR Não são todas as áreas do conhecimento científico que estiveram sempre contempladas na academia. No início apenas as ciências matemáticas, físico-químicas e biológicas estavam representadas. "Os cientistas de maior visibilidade na época eram da área de biológicas, como Osvaldo Cruz, Carlos Chagas, Adolfo Lutz, Juliano Moreira”, conta Carvalho. No aniversário de 80 anos da instituição as engenharias ganharam espaço e, até o ano 2000, incorporaram 10 áreas prioritárias. As ciências sociais foram as últimas a ter representação sendo que a maioria dos membros é formada por cientistas sociais em sentido estrito - economistas, sociólogos, cientistas políticos, antropólogos -, embora haja historiadores, como Carvalho, e juristas.
Ana Paula Hey, da Universidade de São Paulo (USP), em artigo apresentado durante o $38^{\circ}$ Encontro Anual da Associação Nacional de Pós-Graduação e Pesquisa em Ciências Sociais (Anpocs), em 2014, lembrou que a $A B C$ possuía acadêmicos com atuação nas ciências humanas desdea fundação. Dentre os exemplos ela cita membros vindos de áreas tradicionais, como o médico Roquette-Pinto (1884-1954), com atuação voltada para a antropologia e a etnologia, e o engenheiro Everardo Adolpho Backheuser (1879-1951), que fazia pesquisas em geopolítica e geografia.

MULHERES NA CIÊNCIA A primeira mulher a se tornar membro da $\mathrm{ABC}$ foi a polonesa Marie Curie, em 1926, quando já era laureada duplamente pela Academia Sueca com o Nobel. A oceanógrafa Marta Vannucci foi a primeira mulher a ser aceita como membro associado, em 1955. Apenas em 1966 ela se tornou membro titular.

A questão de gênero é prioritária para a $\mathrm{ABC}$ e faz parte das ações políticas. Embora Palis reconheça que o percentual de 14\% ainda está longe do ideal, ele reconhece que houve avanços que colocam o Brasil à frente de academias tradicionais como a francesa $(8 \%)$ e a inglesa (6\%), e no mesmo patamar das instituições da Argentina, Chile e Colômbia. "O sonho é a paridade”, diz Palis. Entre os novos membros, o percentual de mulheres chega aos 25\%. Dentre 69 academias de ciências ao redor do mundo, a média de participação feminina está em $12 \%$ e apenas $40 \%$ das instituições possuem políticas ou comitês dedicados à questão de gênero, como concluiu o documento "Women for science: inclusion and participation in academies of science", publicado no final de 2015 pela Rede Global de Academias de Ciência (IAP).

COMEMORAÇõES Para seu aniversário, a ABC organiza eventos satélites que incluem debates sobre grandes temas como o genoma humano (11 e 12 de dezembro), segurança alimentar (18 e 19 de abril) e o encontro internacional "An open world" (Um mundo aberto), para discutir o compartilhamento de informações entre países. Esta será a segunda edição desse evento, que ocorreu há três anos na Alemanha em função do centenário do prêmio Nobel recebido pelo físico Niels Bohr (1885-1962). Em 1950, ele escreveu uma carta às Nações Unidas em defesa da abertura e do intercâmbio de informaçôes entre países como forma de combater a crise do pós-Segunda Guerra Mundial.

Sob o apropriado título "Um século de ciência: construindo um futuro melhor", a ABC fez sua reunião magna nos dias 4 a 6 de maio, no Museu do Amanhã, Rio de Janeiro, do qual a ABC é apoia- 
dora. $\mathrm{O}$ evento apontou as prioridades da instituiçãao com conferências sobre energia, educação, doenças negligenciadas - como o zika vírus -, segurança alimentar e novas tecnologias. Dentre os convidados estavam o prêmio Nobel Takaaki Kajita (física, 2015), a presidente da Academia Americana de Ciências e editora-chefe da revista Science, Marcia McNutt, o ex-presidente da NAS, Bruce Alberts, e John Hopcroft, da Cornell University, que recebeu o prêmio Turing, em 1986.

Nesse primeiro centenário a $\mathrm{ABC}$ comemora as conquistas e a maior influência na sociedade. Sua atuação, em um país em desenvolvimento, sobretudo diante de uma grave crise que ameaça as conquistas em ciência e tecnologia, se torna ainda mais relevante. Tarefa que a nova diretoria assume a partir de agora. Foram eleitos para presidir a ABC (2016-2019) o físico Luiz Davidovich, com o engenheiro João Fernando Gomes de Oliveira como vice-presidente, os diretores Elibio Leopoldo Rech Filho, engenheiro agrônomo, Francisco Rafael Martins Laurindo, médico, o matemático Hilário Alencar da Silva, o historiador José Murilo de Carvalho e a física Marcia Cristina Bernardes Barbosa, além de seis novos vice-presidentes regionais.

Germana Barata

\section{RESÍDUOS SÓLIDOS}

\section{Lixões continuam}

por toda parte

Em meio a campanhas de combate ao Aedes aegypti, que incluem mosquitos virtuais passeando pelas páginas dos sites de instituições do governo federal, a população de vários municípios brasileiros continua se deparando com um tipo de criadouro que parece se proliferar com a mesma facilidade que os mosquitos: lixo acumulado nas cidades e em áreas rurais. Mesmo assim, em Brasília, onde está o maior lixão a céu aberto das Américas, a 15 km do Palácio do Planalto e do Congresso Nacional, continuam fortes as pressões para que os municípios brasileiros tenham mais tempo para extinguir os lixões.

Após tramitar por 20 anos no Congresso Nacional, a Lei n० 12.305/10 instituiu a Política Nacional de Resíduos Sólidos (PNRS).

A PNRS determina que a gestão de resíduos sólidos tem que ser compartilhada entre os geradores (fabricantes, importadores, distribuidores, comerciantes) e o cidadão. Também proibiu o lançamento de resíduos a céu aberto - o que inclui os lixões -, excetuados os de mineração, e determinou a disposição final ambientalmente adequada dos rejeitos (por exemplo, em aterros sanitários), a ser implantada em até quatro anos após a data de publicação da Lei. Ou seja, até agosto de 2014 .

\section{MAIS DO QUE COLETAR, GERIR}

A necessidade de adiar o fim dos lixões e a construção de aterros, mostra que a gestão de resíduos sólidos urbanos não tem sido prioridade em boa parte dos municípios brasileiros. Gabriela Otero, coordenadora técnica da Associação Brasileira de Empresas de Limpeza Pública e Resíduos Especiais (Abrelpe), lembra que, a rigor, lixões são proibidos desde 1981, quando entrou em vigor a Política Nacional de Meio Ambiente (Lei nº 6.938, de 31/08/1981). Posteriormente, a chamada Lei dos Crimes Ambientais (Lei no 9.605, de 12/02/1998) considerou crime ambiental, passível de pena de um a cinco anos de reclusão, lançar resíduos sólidos, líquidos ou gasosos, ou detritos, óleos ou substâncias oleosas, em desacordo com as exigências estabelecidas em leis ou regulamentos. Otero salienta que o diferencial da PNRS foi regulamentar e estabelecer prioridades no tratamento de resíduos, indicando que não basta coletar, é preciso gerir. A PNRS não trata expressamente 